\section{Combination of methods of thermal and radiation treatment of sediments associated with PCBs - the Delor type}

\author{
Marko Fülöp, \\ Andrea Šagátová (0), \\ Ivan Benkovský, \\ Karel Prokes, \\ Lubica Foltinova
}

\begin{abstract}
An efficient method of burning polychlorinated biphenyls (PCBs) is often used to remove the environmental burden of PCBs. However, combustion produces toxic dioxins and furans (PCDD/F), so residents are increasingly rejecting this method. The heat treatment (HT) method does not burn PCBs but evaporates it from sediments. Even in this process, PCDD/Fs are formed to a lesser extent, which are destroyed by radiation processing (RP) following the HT. At the same time, the RP method degrades PCB congeners down to biphenyls, which decompose easily in the environment. A block assembly of a complex synergistic combination of equipment for methods of thermal (HT) and radiation (RP) destruction of PCBs in sediments is proposed. The efficacy of this complex was preliminarily determined at a level of 70 -fold reduction in PCB concentration in sediments. To achieve a higher reduction factor in the concentration of PCBs, possible procedures for optimizing the settings of individual devices of this complex are presented.
\end{abstract}

Keywords: Electron beam $\bullet$ Heat treatment $\bullet$ Polychlorinated biphenyls $\bullet$ Radiation degradation

M. Fülöp ${ }^{\bowtie}$

ABRS Ltd.

Pomlejská 106, 93101 Šamorín, Slovak Republic

E-mail: marko.fulop@gmail.com

\section{A. Šagátová}

Slovak University of Technology in Bratislava Institute of Nuclear and Physical Engineering Faculty of Electrical Engineering and Information

Technology

Ilkovičova 3, 81219 Bratislava, Slovak Republic

I. Benkovský

Comenius University in Bratislava

Faculty of Pharmacy

Odbojárov 10, Bratislava, Slovak Republic

K. Prokes

AGMECO LT, s.r.o.

Türkova 828, Praha 4, 14900 Czech Republic

L. Foltinova

UEBA, University of Economics in Bratislava

Dolnozemská cesta 1, 85235 Bratislava, Slovak Republic

Received: 3 January 2021

Accepted: 8 April 2021

\section{Introduction}

The environment in the area of $40 \times 80 \mathrm{~km}^{2}$ of the Michalovce district in Slovakia with 200000 inhabitants has a 60-year-old ecological burden from the period of PCB production in Chemko Strážske. For $>20$ years, the spatial monitoring of PCB concentrations in environmental components, such as sediments of watercourses and reservoirs, soil, and air has been systematically performed.

Great attention was paid to the spatial distribution of specific PCB congeners determined based the measurements of the concentration of 15 PCB congeners in the blood serum of adults, children, and couples of mothers and children born in 2001-2003. These were long-term residents living up to $70 \mathrm{~km}$ in north and up to $50 \mathrm{~km}$ in south from the former PCB Chemko Strážske production plant in the Michalovce district. The concentrations of PCB congeners in inhabitants' blood were indirectly related to the distance of their residence from the source of pollution. Congener-specific risk factors were derived, in particular, for PCB congeners 52 and 153.

It was concluded that about 200000 people were at risk in this densely populated area 10 years ago. This environmental burden is still one of the largest in the world [1-3].

The paper presents preliminary verification experiment of the combination of the methods of heat

0029-5922 @ 2021 The Author(s). Published by the Institute of Nuclear Chemistry and Technology.

This is an open access article under the CC BY-NC-ND 4.0 licence (http://creativecommons.org/licences/by-nc-nd/4.0/). 


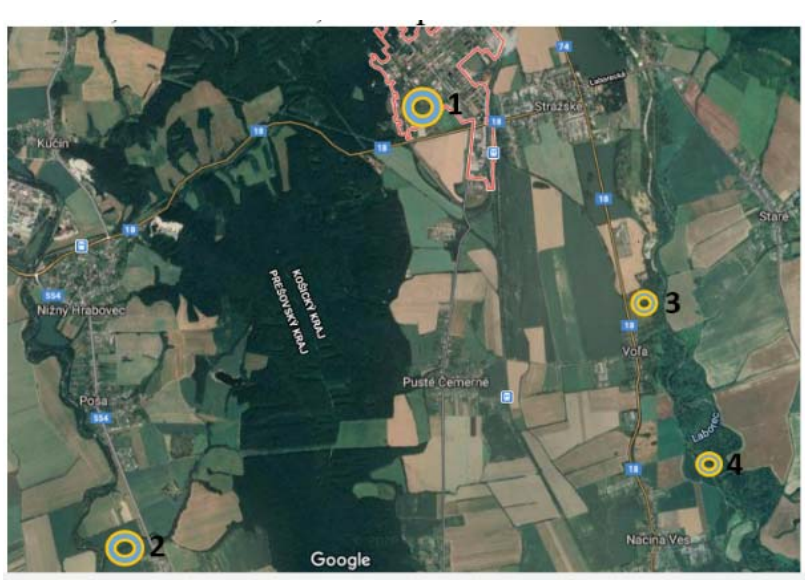

Fig. 1. Positions of current main sources of environmental load of PCBs in Eastern Slovakia.

treatment (HT) and radiation cleaning for canal sediments from Delor-type PCBs contamination that is hundred times higher than the permissible level.

\section{Experiments}

The main sources of environmental load by PCBs in Eastern Slovakia (Fig. 1) are given below:

1. In the Chemko Strážske complex, there are containers with 500 tons of $\mathrm{PCB}$ waste.

2. Poša tailings pond, a source of dust with PCBs carried by the wind.

3. In Strážský canal, there are 4000 tons of sediments contaminated by PCB in averaged concentration of $53 \mathrm{mg} / \mathrm{kg}$ [4].

4. Containers with a concentration PCB waste in the forest.

The environment can be divided into those that are spatially modified, such as containers with PCB waste and PCB sources enclosed in controlled areas (Chemko Strážske complex and Pošeň tailings pond). Small containers with PCB waste in the environment and in the Chemko Strážske complex can be handed over for disposal. The Pošeň tailings pond can be secured in the classic conventional way against the release of PCBs into the environment. The canal still releases PCB-contaminated sediments, which further contributes to new environmental contamination. Based on the data from long-term monitoring, it is necessary to monitor the situation in the environment to a depth of approximately $30 \mathrm{~cm}$. The purpose of in-depth sampling is to determine the average thickness of sediments through which PCBs still penetrate in a concentration that exceeds the level of the maximum permitted value laid down by the Act No. 188/2003 Collection of Laws of the Slovak Republic. The act defines limits for PCB concentration in sediments, which is $0.8 \mathrm{mg} / \mathrm{kg}$ for the sum of seven selected PCB congeners: $28,52,101,118,138,153$, and 180 . Their chemical structure can be seen in Fig. 2 .

An expensive PCB incineration method is often used to remove the environmental burden of PCBs. However, the combustion process produces toxic dioxins and furans (hereinafter also referred to as $\mathrm{PCDD} / \mathrm{Fs}$ ) and hence additional expensive equipment is needed to remove these dioxins and furans, so PCB incinerators are stable facilities into which waste from a wide area is imported. For this reason, residents demand that non-incineration methods of relocatable PCBs are used to regenerate their PCB-contaminated environment.

The preliminary estimated level of PCB concentration in the sediments of the Strážský canal is relatively high (approximately one hundred times higher than the maximum allowed value). Therefore, additional methods of HT and radiation treatment (RP) were chosen to reduce the concentration of PCBs in the sediments.

The first HT method is effective for destroying PCBs in sediments. However, the HT method is also a process in which toxic dioxin-like selected PCB congeners (DL-PCBs) 77, 81, 105, 114, 118, $123,126,156,157,167,169$, and 189 in the solid, liquid, and gaseous state are by-products. Electron beam (EB) irradiation is an effective method to remove these toxic products. Both HT and RP methods are complementary and their interconnection to achieve a synergistic effect is shown in Fig. 3. After applying the HT method, the RP method is preferably used, which is also effective in removing DL-PCBs (PCDD/Fs). The RP radiation treatment method also removes PCBs from liquid condensates by gradual degradation of congeners until they are converted to biphenyls, which decompose easily in the environment. The products of the radiochemical degradation reactions of PCBs may gradually accumulate, leading to a reduction in the efficiency of the RP method. In this case, the treated sample is cleaned as shown in Fig. 3.

A linear electron accelerator to the energy of $5 \mathrm{MeV}$ University Centre of Electron Accelerators (UCEA) of the Slovak Medical University in Trenčín for EB irradiation of sediment samples, a mobile device of AGMECO Ltd. in Prague for the HT of sediments, and a certified laboratory of the Slovak Medical University in Bratislava for the analysis of PCBs in sediment samples were used.

The radiation method also decomposes dioxin/ furans (PCDD/Fs) from sediments and from the liquid that is a by-product of sediment when the HT method is applied.

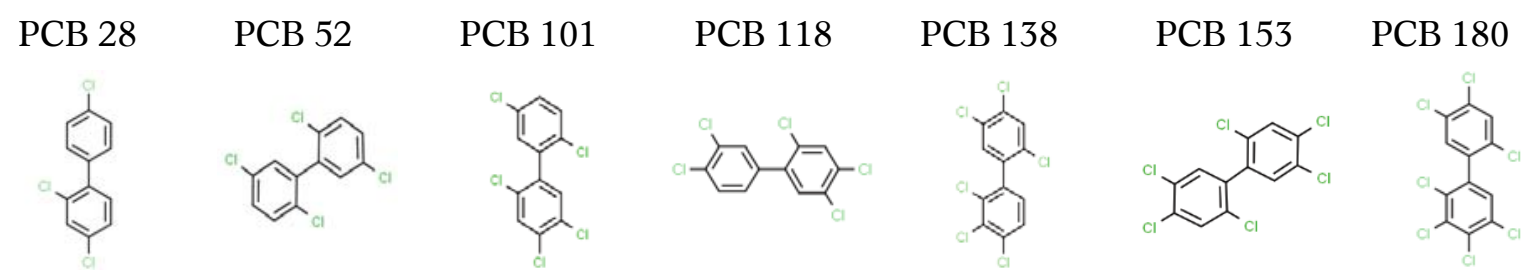

Fig. 2. Chemical structures of selected PCB congeners. 


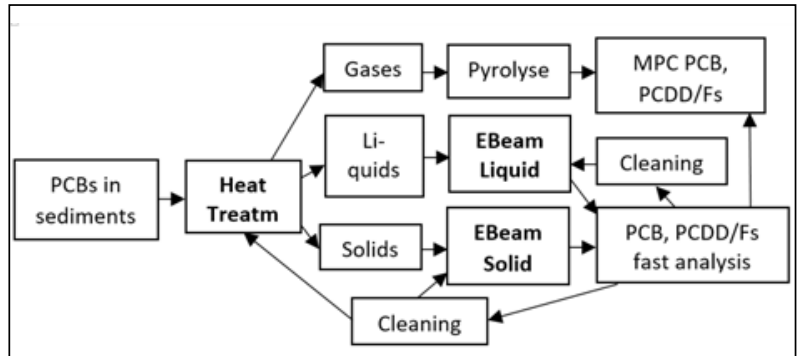

HT-HeatTreatm - destruction of PCBs, destruction of PCDD/ Fs in gas, possible by-products PCB and PCDD/Fs in liquids. EBeamLiquid - radiation processing for $\mathrm{PCB}$ destruction in liquids: destruction of PCBs and PCDD/Fs in liquids.

EBeamSolid - radiation destruction in solids: destruction of PCB in sediments after heat treatment.

PCB, PCDD/Fs - PCB or PCDD/Fs concentrations that are lower than the maximum permissible concentration of PCB in sediments.

Cleaning - purification of irradiated materials from

radiochemical reaction products (e.g. biphenyl accumulation) and restoration of the chemical environment for further

efficient electron beam irradiation.

Fig. 3. Block diagram of the design of optimization of interconnection of HT methods with radiation treatment method in their complementary interaction.
The presentation uses the possibility of using the complementarity of these two methods to increase the efficiency of PCB removal from sediments of the contaminated environment.

Technologies of both methods can be installed on a relocatable device.

\section{Results and discussion}

Figure 4 shows the concentration dependences of non-dioxin-like PCB congeners (NDL PCBs) in samples of sediments chemically prepared by co-solvents $\mathrm{K}_{2} \mathrm{CO}_{3}$ [5] and 2-propanol [6] and treated by RP [7]. The values of NDL PCB congeners were significantly reduced after irradiation by $\mathrm{EB}(5 \mathrm{MeV})$ with a dose of $100 \mathrm{kGy}$ to $200 \mathrm{kGy}$ when $\mathrm{K}_{2} \mathrm{CO}_{3}$ co-solvent was used.

Figure 5 compares the concentrations of NDL-PCB congeners in untreated sediment samples with concentrations in samples processed first by the $\mathrm{HT}$ followed by radiation degradation by $5 \mathrm{MeV}$ electrons using $\mathrm{K}_{2} \mathrm{CO}_{3}$ co-solvent.

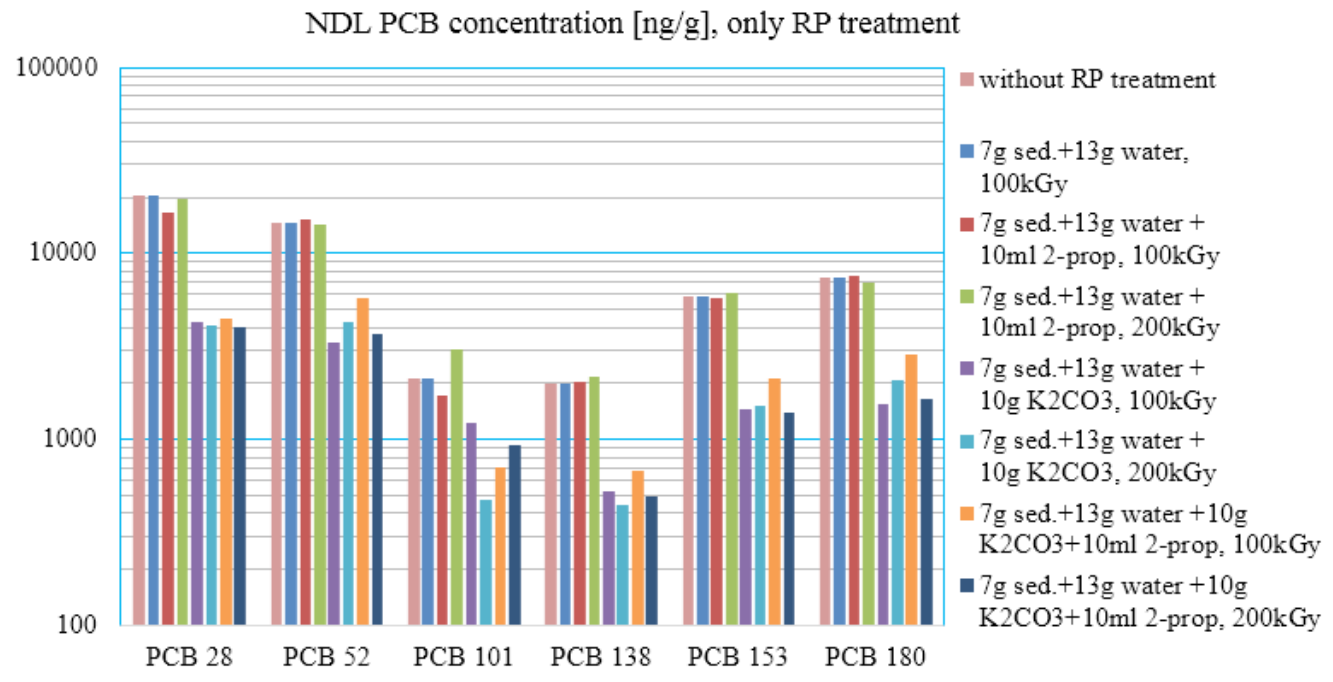

Fig. 4. Concentrations of NDL-PCBs in samples of sediments treated with RP.

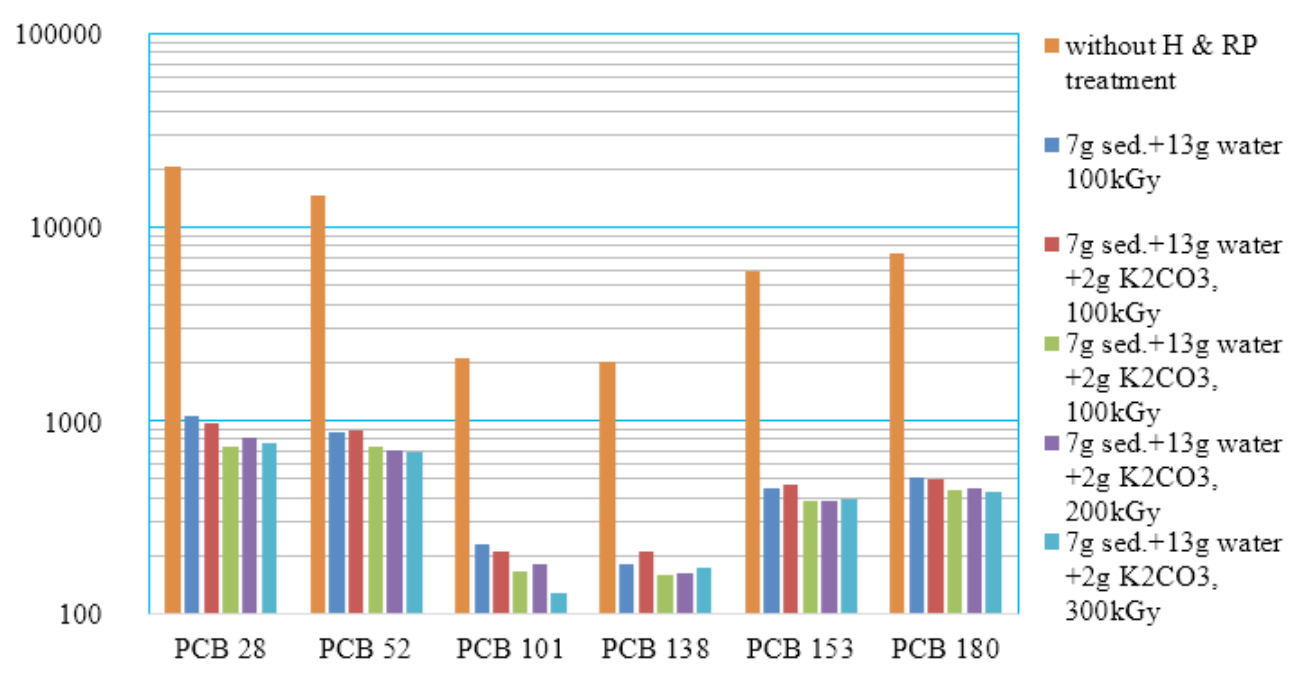

Fig. 5. Comparison of NDL-PCB concentrations in untreated sediment samples with RP-treated samples following HT. 
Table 1. NDL-PCB concentration (ng/g) in sediments

\begin{tabular}{lccc}
\hline \multicolumn{1}{c}{ Treatment } & $\mathrm{RP}(5 \mathrm{MeV} / 100 \mathrm{kGy})^{*}$ & $\mathrm{HT}\left(500^{\circ} \mathrm{C} / 30 \mathrm{~min}\right)$ & $\mathrm{HT}+\mathrm{RP}^{* * *}$ \\
\hline Without RP or HT & 52200 & 52200 & 52200 \\
With RP and/or HT & 12348 & 3280 & 2900 \\
PCB concentration reduction factor & 4.2 & 16.0 & 18.0 \\
\hline
\end{tabular}

"Chemical pre-treatment of sediment samples: $7 \mathrm{~g}$ dry sediment $+13 \mathrm{~g}$ water $+10 \mathrm{~g} \mathrm{~K}_{2} \mathrm{CO}_{3}$.

"Chemical pre-treatment of sediment samples: $7 \mathrm{~g}$ dry sediment $+13 \mathrm{~g}$ water $+2 \mathrm{~g} \mathrm{~K}_{2} \mathrm{CO}_{3}$.

Table 2. Reduction of DL-PCB concentration (ng/g) in sediments by RP method depending on their chemical pretreatment

\begin{tabular}{lcc}
\hline \multicolumn{1}{c}{ Treatment } & $\mathrm{RP}(5 \mathrm{MeV} / 300 \mathrm{kGy})^{*}$ & $\mathrm{RP}(5 \mathrm{MeV} / 100 \mathrm{kGy})^{* * *}$ \\
\hline Without RP & 4630 & 6400 \\
With RP & 4050 & 1560 \\
Concentration reduction factor & 1.14 & 4.1 \\
\hline
\end{tabular}

"Chemical pre-treatment: $7 \mathrm{~g}$ dry sediment $+13 \mathrm{~g}$ water $+2 \mathrm{~g} \mathrm{~K}_{2} \mathrm{CO}_{3}$.

* Chemical pre-treatment: $7 \mathrm{~g}$ dry sediment $+13 \mathrm{~g}$ water $+10 \mathrm{~g} \mathrm{~K}_{2} \mathrm{CO}_{3}$.

Table 3. Concentrations of NDL-PCB and DL-PCB (ng/g) in dried sediments and in liquid condensate after HT

\begin{tabular}{lcc}
\hline \multicolumn{1}{c}{ Substance } & $\begin{array}{c}\text { Dried } \\
\text { sediments }\end{array}$ & $\begin{array}{c}\text { Liquid } \\
\text { condensate }\end{array}$ \\
\hline NDL-PCB & 3280 & 78.9 \\
DL-PCB & 463 & 69.4 \\
Weight $\%$ & 39.5 & 56 \\
\hline
\end{tabular}

The spectrum of congeners has been changed after HT. Nevertheless, the addition of $\mathrm{K}_{2} \mathrm{CO}_{3}$ to these HT treated samples again led to a significant reduction in PCB concentrations in sediments after RP. The first results have already shown that the combination of the HT and RP methods for destruction of PCBs is promising. Table 1 shows the values of reduced $\mathrm{PCB}$ concentrations in sediments (sum of NDL PCB congeners) only by processing RP radiation and both HT and subsequently RP.

The differences between HT and the next RP are small, and the PCB concentration reduction factor changes from 16 to 18 . An increase in the reduction factors in Table 1 can be achieved by optimizing the operating parameters of one or both complementary methods. For example, by increasing the temperature at HT or by changing EB parameters such as electron energy, intensity, and irradiation geometry, as well as by adjusting the chemical pre-treatment of the sediment samples as shown in Table 2 .

Table 3 shows the concentrations of NDL-PCB and DL-PCB in the dried sediments and in the liquid condensate after HT.

Liquid condensate is formed in HT in the predominant amount compared to dry sediment and contains a significant concentration of DL congeners, which can be removed by RP methods $[8,9]$.

The rest of the PCB after the HT, which is in the gas phase, is discharged to a special device, where it is completely removed by pyrolytic treatment, according to Fig. 3.

\section{Conclusions}

The complex of synergistic interconnection of two complementary methods of gentle removal of PCBs from sediments by thermal (HT) and radiation (RP) destruction of NDL-PCB and DL-PCB in sediments and liquids was experimentally verified. In the first stage, when setting the complexes of operating parameters, a 70 -fold reduction in the concentration of PCBs from sediments was achieved. The paper shows examples of possible procedures for optimizing the operating parameters of the complex so as to achieve a higher factor of reducing the concentration of PCBs in sediments.

Acknowledgment. This work was financially supported by the International Atomic Energy Agency by CRP F23034 under Research Contract No. 24270 "Optimization of Radiation Degradation of PCB Contaminated Sludge by Chemical Pre-treatment" and by the IAEA TC project RER1021 "Enhancing the Use of Radiation Technologies in Industry and Environment".

\section{ORCID}

A. Šagátová (D) https://orcid.org/0000-0002-8519-7206

\section{References}

1. van der Berg, M., Kypke, K., Kotz, A., Trischer, A. Lee, S. Y., Magulova, K., Fiedler, H., \& Malish, R. (2017). WHO/UNEP global surveys of PCDDs, PCDFs, PCBs and DDTs in human milk and benefitrisk evaluation of breastfeeding. Arch. Toxicol., 91, 83-96. DOI: 10.1007/s00204-016-1802-z.

2. Besret, C., Tard, A., Merlo, M., Narbonne, J. F., Leblanc, J. C., \& Rivière, G. (2011). Set-up of critical PCB body burden values. In Proceedings of the 31st International Symposium on Halogenated Persistent Organic Pollutants, Dioxin, 2011, 3505 pdf.

3. Horvathova, M., Jahnova, E., Palkovičova, L., Trnovec, T., \& Hertz-Picciotto, I. (2011). Dynamics of lymphocyte subsets in children living in an area polluted by polychlorinated biphenyls. J. Immunotoxicol., 8, 333-345.

4. Danielovič, I., Hecl, J., \& Danilovič, M. (2014). Soil contamination by PCBs on a regional scale: the Case 
of Strážske. Pol. J. Environ. Stud., 23(5), 1547-1554.

5. Darážová, L., Šagátová, A., Nečas, V., Fülöp, M., \& Han, B. (2016). Radiation degradation of PCBs in sediments: comparison between two methods. Acta Polytechnica CTU Proceedings, 4, 19-21. DOI: 10.14311/AP.2016.4.0019.

6. Singh, A., \& Kremers, W. (2002). Radiolytic dechlorination of polychlorinated biphenyls using alkaline 2-propanol solutions. Radiat. Phys. Chem., 65, 467-472. DOI: 10.1016/S0969-806X(02)00360-2.

7. Trifan, A., Calinescu, I., \& Martin, D. (2009). Transformation of polychlorinated biphenyls (PCBs) into non-hazardous products by electron beam treatment Rev. Chim. (Bucuresti), 60(10), 1053-1055.

8. Múčka, V., Sílber, R., Pospíšil, M., Kliský, V., \& Kropáček, M. (1998). Způsob radiační dechlorace chlorovaných organických látek a zařízení k provádění způsobu, Patent No. 283198. Prague.

9. Múčka, V., Buňata, M., Čuba, V., Silber, R., \& Juha, L. (2015). Radiation induced dechlorination of some chlorinated hydrocarbons in aqueous suspensions of various solid particles. Radiat. Phys. Chem., 112, 108-116. DOI: 10.1016/j.radphyschem.2015.03.029. 